\title{
Fever in children: how to minimise risk and provide appropriate therapy
}

\author{
Robin J Green ${ }^{\mathrm{a}^{*}}$ and Adéle Pentz ${ }^{\mathrm{a}}$ \\ a Department of Paediatrics and Child Health, University of Pretoria, Pretoria, South Africa On behalf of the South African Fever Management Committee \\ *Corresponding author, email: robin.green@up.ac.za
}

The management of fever in children is a subject that garners many different opinions and interventions. Various approaches seem to be acceptable, from the physician who never uses antipyretic medication, to the use of multiple combination therapies. Following the recent publication of guidelines for the management of acute fever in children, there is now a standard against which fever in children should be managed. These guidelines aim to standardise the process of examining pyrexial children, elicit a reasonable history and then investigate the likely illnesses, so as to justify appropriate therapy.

Keywords: children, fever, management, risk, therapy

\section{Introduction}

The management of fever in children is a subject that garners many different opinions and interventions. Various approaches seem to be acceptable, from the physician who never uses antipyretic medication, to the use of multiple combination therapies. Following the recent publication of guidelines for the management of acute fever in children, there is now a standard according to which fever in children should be managed. These guidelines aim to standardise the process of examining pyrexial children, elicit a reasonable history and then investigate likely illnesses, so as to justify appropriate therapy.

\section{What is fever?}

The human body functions optimally at defending itself against infectious and noxious agents at a higher body temperature. Fever is a normal physiological response to illness, which facilitates and accelerates recovery. Fever in children often drives the use (or abuse) of antipyretic medication by parents who fear its consequences, especially pyrexial convulsions. ${ }^{1,2}$

Unfortunately, fever and the degree of fever do not predict the underlying cause, e.g. whether or not it is caused by a viral or bacterial illness. Therefore, fever is not a diagnosis. Every attempt must be made to identify the source and to exclude a more sinister cause for which appropriate medication would be required.

Recently, guidelines were developed and published to assist pharmacists, primary healthcare workers and general practitioners in risk stratifying children who present with fever, to decide on when to refer, the appropriate use of antipyretic medication and how to advise parents and caregivers. ${ }^{3}$

\section{Definition of fever and general principles \\ Fever is defined as a body temperature $\geq 38^{\circ} \mathrm{C} .{ }^{3}$}

\section{Measurement of body temperature}

Body temperature must be measured in the ear, using an infrared tympanic thermometer, or in the axilla ${ }^{3}$. Oral and rectal routes should not be used to measure body temperature in a child. If using a glass thermometer, before inserting it in the axilla, it is important to shake the thermometer until the liquid is below the $36{ }^{\circ} \mathrm{C}$ line. Reusable thermometers should be washed between use. Temperature must not be measured directly after bathing.

\section{Infrared tympanic (ear) measurement}

Gently pull backwards (posteriorly) on the ear lobe to open the ear canal when carrying out an infrared tympanic (ear) measurement. ${ }^{3}$ The probe of the thermometer should be inserted into the ear canal and the activation button pressed until a beep is heard. The thermometer can then be removed from the ear and the temperature read on the liquid-crystal display screen.

Table 1 lists important questions which should be asked of parents to determine whether or not children require immediate examination by a doctor.

\section{Medical history and examination by a clinician}

Fever is not a diagnosis, but a symptom of an illness. A diagnosis of the underlying illness is essential in order to institute appropriate treatment.

It is important to ascertain information on the following: ${ }^{3}$

- Fever onset, duration, whether it has been continuous or intermittent, and the child's response to general measures or medication.

- Associated signs and symptoms.

- Recent use of antibiotics.

- Recent vaccinations (within 48 hours) and vaccination history.

- Recent travel.

- Health of the other family members, exposure to sick individuals, and if the child attends crèche or school.

- Previous illnesses, including those relating to immunodeficiency, as well as chronic illnesses.

- The child's activity level.

\section{Examination}

It is critical that an examination is conducted to determine if the child is at high risk of serious illness (Table 2).

\section{General considerations}

The degree of fever doesn't usually predict the seriousness of the underlying illness. ${ }^{4}$ The response of the fever to antipyretic medication is also not a predictor of the nature of the underlying illness. ${ }^{4}$ An antibiotic does not treat fever. Antibiotics should only be administered if there is suspicion or proof of a bacterial illness. ${ }^{1}$ 
Table 1: Important questions that need to be asked to determine if a child with fever needs to seek medical care

- Is the child younger than three months of age?

- Is the child eating and drinking normally?

- Is the child breathing normally?

- Is the child behaving normally?

- Has the fever lasted for more than two days?

- Have any convulsions taken place?

- Are you concerned?

Table 2: Children at high risk with associated fever

- Unable to rouse, of if roused, unable to stay awake

- A weak, high-pitched or continuous cry

- A pale, mottled, blue or ashen appearance

- Reduced skin turgor

- Moderate or severe chest indrawing

- A respiratory rate $>60$ breaths/minute

- Grunting

- A bulging fontanelle

- Appearing ill to a healthcare professional

- Age $<3$ months of age, with a temperature $\geq 38^{\circ} \mathrm{C}$

- Age 3-6 months of age, with a temperature $\geq 39^{\circ} \mathrm{C}$

- A non-blanching rash

- Neck stiffness or focal neurological signs

- Focal seizures

- Bile-stained vomiting

Empirical antibiotics for possible occult bacteraemia in children $>3$ months of age do not confer any significant advantage. ${ }^{4}$ However, if the child has signs of severe sepsis or septic shock, parenteral antibiotics should be administered within the first hour of healthcare contact.

General advice should be given to parents with uncertain follow-up, e.g. if they lack transport, there is a parental perception that the child is not that ill, or the parents do not have access to a telephone.

\section{Discomfort caused by pain and fever}

Discomfort during a febrile illness is often a consequence of associated pain, e.g. myalgia, a sore throat and headaches. Antipyretic medication, e.g. ibuprofen and paracetamol, improves comfort, with accompanying advances in feeding activity and irritability, because it also provides pain relief and may reduce the risk of dehydration. ${ }^{2}$

\section{Antipyretic medication}

Antipyretic medication should be used to make the child more comfortable, rather than used routinely with the sole aim of reducing temperature. ${ }^{1,2}$ The use of antipyretic medication and attention to the fever must not detract from ensuring that the child's activity and level of consciousness (as an indicator of worsening illness) are both monitored, and that attention is given to adequate hydration. Ibuprofen and paracetamol are safe and effective for short-term use in children., ${ }^{2,-11}$ The practice of combining or alternating paracetamol and ibuprofen has limited value and is not recommended. ${ }^{12-14}$

Mefenamic acid is registered for use from six months of age, and may be an alternative nonsteroidal anti-inflammatory drug (NSAID) to ibuprofen in children with fever. The recommended dose is $6.5 \mathrm{mg} / \mathrm{kg}$ body weight, not more than three times daily. Care should be taken to avoid overdosing. ${ }^{15,16}$ Dosing of antipyretic medication in children must be accurately based on body weight and should not be estimated (Table 3). Contraindications and precautions to the use of antipyretic drugs in children are listed in Table 4. Aspirin should not be used in children or adolescents younger than 18 years of age because of the risk of Reye's syndrome. The use of NSAIDs has been associated with an elevated risk of severe skin and soft tissue infection in patients with varicella-zoster virus infection. ${ }^{17-19}$ Therefore, paracetamol is recommended as the antipyretic of choice in children with chicken pox. Medicines containing a combination of NSAIDs, paracetamol, codeine and/or antihistamines should not be used in children. Liquid medicines must be administered with a syringe to ensure accurate dosing.

\section{Vaccination and fever}

Fever and a local reaction (pain, swelling and redness) are normal reactions to vaccination and are not harmful. The prophylactic administration of antipyretic drugs at the time of vaccination is associated with reduced antibody responses to vaccine antigens. ${ }^{21}$ Antipyretic medication should not be administered either as treatment for a local inflammatory reaction or fever, or prophylactically to prevent a local inflammatory reaction or fever from occurring. Antipyretic medication may be used to make the child more comfortable in the event of complications associated with vaccination, such as cellulitis or systemic complications.

\section{Advice for parents caring for the child at home}

A child with a fever is very distressing to parents. While management of the underlying cause is important, it is just as important to provide parents with the advice and necessary tools to manage the child's fever in a way that allays fear. Clear instructions are important. It is critical to provide reassurance that the fever itself does not necessarily require treatment as it is a symptom of an illness requiring a diagnosis, in order for specific and appropriate treatment to be implemented.

\section{Five clear principles}

Five clear principles need to be expounded. ${ }^{3}$

\section{Reassure anxious parents about the child's fever}

Fever is not an illness, but a beneficial response by the body to illness. Most fever is of a short duration and is not harmful. Children with fever are not at increased risk of a seizure,

Table 3: Dose of antipyretic medication in children aged three months and older ${ }^{2,20}$

\begin{tabular}{llll}
\hline Antipyretic medication & Oral dose & Dose frequency & Maximum daily dose \\
\hline Ibuprofen & $10 \mathrm{mg} / \mathrm{kg}$ body weight & Every 6 hours & $40 \mathrm{mg} / \mathrm{kg}$ \\
Paracetamol & $15 \mathrm{mg} / \mathrm{kg}$ body weight (up to $1 \mathrm{~g})$ & Every 4 hours & $90 \mathrm{mg} / \mathrm{kg}(4 \mathrm{~g}$ in total) \\
\hline
\end{tabular}


Table 4: Contraindications and precautions to the use of antipyretic drugs in children ${ }^{21}$

\begin{tabular}{lll}
\hline & Nonsteroidal anti-inflammatory drugs & Paracetamol \\
\hline Contraindications & $\begin{array}{l}\text { Hypersensitivity, active peptic ulceration or upper } \\
\text { gastrointestinal bleeding, severe renal failure, and } \\
\text { hepatic or cardiac failure }\end{array}$ \\
Precautions & $\begin{array}{l}\text { Asthma, cardiac disease, dehydration, the con- Hepatic impairment, renal impairment and } \\
\text { comitant use of drugs which increase the risk of overdosing } \\
\text { bleeding, previous peptic ulceration, coagulation } \\
\text { defects, allergic disorders, and renal or hepatic } \\
\text { impairment }\end{array}$ \\
\hline
\end{tabular}

dehydration, brain damage or death. The body temperature normally fluctuates during a fever which runs its course in a few days, but returns until the illness has resolved. Strict control of the fever is never required.

\section{Advise parents on how to manage fever at home}

Tepid sponging is not recommended. The child should not be over- or underdressed, nor wrapped in heavy blankets. Drinking fluids regularly should be encouraged. Breast milk is best for breastfeeding children. Parents should speak to their doctor or pharmacist first before administering medication for fever to ensure that the correct medicine is given at the right dose. The child should be checked during the night, but not woken merely to receive antipyretic medication. Further medical advice can be sought if the fever does not improve within 48 hours, or the child's condition worsens.

\section{Give clear instructions on how the medication should be administered}

It is important to give the correct dose. Tell the parents how to measure the dose and how often to administer it. Parents must be warned not to exceed the prescribed dose or dosing interval. The bottle has to be shaken before pouring. Medicine should never be measured using a household teaspoon or tablespoon. Only the measuring device provided should be used. Unless a measuring device is packed together with the medicine, caregivers must be provided with an appropriate syringe or measuring spoon. This should occur whenever medicine is dispensed to a child. Children must never be allowed to drink medicine straight from the bottle. Medicine must be stored out of the reach of children.

\section{Advise parents on the correct use of antipyretic medication}

Antipyretic medication should be used to make the child more comfortable, rather than routinely used for the sole purpose of reducing the temperature. It does not prevent febrile convulsions and should not be used specifically for this purpose. ${ }^{1}$ Doses must be carefully measured to avoid over- or underdosing. Antipyretic medication starts to work within 1-3 hours. Another dose must not be administered ahead of the appropriate time if a child's temperature does not fall after one dose. If the child vomits immediately after taking a dose of the medicine, another dose may be given. Antipyretic medication does not reduce body temperature to normal unless the fever is low to begin with. Sleeping children should not be awakened solely for the purpose of administering an anytipyretic. Combination products and the administration of "cough and cold medicine" should be avoided as they complicate dosing, and may increase the risk of overdosing and side-effects. Antipyretic medication should not be administered for longer than two days without a doctor being consulted.

\section{Provide written instructions about follow-up}

Written instructions should be provided to parents on the follow-up of the child.

\section{Conclusion}

Fever is frightening to parents, especially if the children are young. The diagnosis of potentially serious causes, through taking a careful history and conducting an examination, is important. Fever caused by common viral infections in children is often benign and self-limiting. The main purpose of antipyretic medication is to relieve discomfort, rather than "chase down a fever".

Parents and healthcare providers need to be reassured when the risk of serious illness is low. The child can be managed appropriately at home with antipyretic medication if there are indications that this will make him or her more comfortable. Clear instructions to parents and caregivers on when to seek further care for their children helps to reduce the morbidity associated with childhood illnesses.

\section{References}

1. Feverish illness in children. Assessment and management in children younger than 5 years. London: National Institute for Health and Clinical Excellence; 2007.

2. Section on Clinical Pharmacology and Pharmaceutics, Committee on Drugs, Sullivan JE, Farrar HC. Fever and antipyretic use in children. Pediatrics. 2011;127(3):580-7. http://dx.doi.org/10.1542/peds.2010-3852

3. Green RJ, Jeena P, Kotze S, et al. Management of acute fever in children: guideline for community healthcare providers and pharmacists. S Afr Med J. 2013;103(12):948-54. http://dx.doi.org/10.7196/samj.7207

4. Luszczak M. Evaluation and management of infants and young children with fever. Am Fam Phys. 2001;64(7):1219-26.

5. Goldstein B, Giroir B, Randolph A. International consensus conference on pediatric sepsis. International pediatric sepsis consensus conference: definitions for sepsis and organ dysfunction in pediatrics. Pediatr Crit Care Med. 2005;6(1):2-8.

6. Plaisance KL. Toxicities of drugs used in the management of fever. Clin Infect Dis. 2000;31(Suppl 5):S219-23. http://dx.doi.org/10.1086/317518

7. Goldman RD, Ko K, Linett LJ, Scolnik D. Antipyretic efficacy and safety of ibuprofen and acetaminophen in children. Ann Pharmacother. 2004;38(1):146-50.

8. Perrott DA, Piira T, Goodenough B, Champion D. Efficacy and safety of acetaminophen vs ibuprofen for treating children's pain or fever: a meta-analysis. Arch Pediatr Adolesc Med. 2004;158(6):521-6. http://dx.doi.org/10.1001/archpedi.158.6.521

9. Pierce CA, Voss B. Efficacy and safety of ibuprofen and acetaminophen in children and adults: a meta-analysis and qualitative review. Ann Pharmacother. 2010;44(3):489-506. http://dx.doi.org/10.1345/aph.1M332

10. Kauffman RE, Sawyer LA, Scheinbaum ML. Antipyretic efficacy of ibuprofen vs acetaminophen. Am J Dis Child. 1992;146(5):622-5.

11. Van Esch A, Van Steensel-Moll HA, Steyerberg EW, et al. Antipyretic efficacy of ibuprofen and acetaminophen in children with febrile seizures. Arch Pediatr Adolesc Med. 1995;149(6):632-7. http://dx.doi. org/10.1001/archpedi.1995.02170190042007

12. Hay AD, Costelloe C, Redmond NM, et al. Paracetamol plus ibuprofen for the treatment of fever in children (PITCH): randomised controlled trial. BMJ. 2008;337:a1302. http://dx.doi.org/10.1136/bmj.a1302

13. Purssell E. Systematic review of studies comparing combined treatment with paracetamol and ibuprofen, with either drug alone. Arch Dis Child. 2011;96(12):1175-9. http://dx.doi.org/10.1136/ archdischild-2011-300424 
14. Pereira GL, Dagostini JM, Pizzol Tda S. Alternating antipyretics in the treatment of fever in children: a systematic review of randomized clinical trials. J Pediatr (Rio J). 2012;88(4):289-96. http://dx.doi.org/ 10.2223/JPED.2204

15. Public assessment report for paediatric studies submitted in accordance with Article 45 of Regulation (EC) No1901/2006, as amended. Mefenamic Acid UK/W/037/pdWS/001. Heads of Medicines Agencies [homepage on the Internet]. c2012. Available from: http://www.hma.eu/ fileadmin/dateien/Human_Medicines/CMD_h_/Paediatric_Regulation/ Assessment_Reports/Article_45_work-sharing/Mefenamic_acid_Art.45_PublicAR.pdf. [Accessed 12 September 2012]

16. Smolinske SC, Hall AH, Vandenberg SA, et al. Toxic effects of nonsteroidal anti-inflammatory drugs in overdose: an overview of recent evidence on clinical effects and dose-response relationships. Drug Saf. 1990;5(4): 252-74. http://dx.doi.org/10.2165/00002018-199005040-00 003

17. Mikaeloff Y, Kezouh A, Suissa S. Nonsteroidal anti-inflammatory drug use and the risk of severe skin and soft tissue complications in patients with varicella or zoster disease. Br J Clin Pharmacol. 2007;65(2):203-9.
18. Dubos F, Hue V, Grandbastien B, et al. Bacterial skin infections in children hospitalized with varicella: a possible negative impact of non-steroidal anti-inflammatory drugs? Acta Derm Venereol. 2008;88(1):26-30. http:// dx.doi.org/10.2340/00015555-0333

19. Souvri C, Olivier P, Grolleau S, et al. Severe necrotizing soft-tissue infections and nonsteroidal anti-inflammatory drugs. Clin Exp Dermatol. 2008;33(3):249-55.

20. World Health Organization. WHO guidelines on the pharmacological treatment of persisting pain in children with medical illnesses. WHO [homepage on the Internet]. 2012. Available from: http://apps.who. int/medicinedocs/en/m/abstract/Js19116en/

21. Prymula R, Siegrist CA, Chlibeck R, et al. Effect of prophylactic paracetamol administration at time of vaccination on febrile reactions and antibody responses in children: two open-label, randomized controlled trials. Lancet. 2009;374(9698):1339-50. http://dx.doi. org/10.1016/S0140-6736(09)61208-3 